\title{
Summary of the Consultation on a Strategy for Services for Chronic Obstructive Pulmonary Disease (COPD) in England
}

\author{
*Rupert Jonesa, Kevin Gruffydd-Jones ${ }^{b}$, Hilary Pinnockc, Sarah-Jane Peffers ${ }^{d}$, \\ Judith Lawrence ${ }^{\mathrm{e}}$, Jane Scullion ${ }^{\dagger}$, Patrick White ${ }^{\mathrm{g}}$, Steve Holmes ${ }^{\mathrm{h}}$
}

a General Practitioner, and Honorary Clinical Lecturer, Peninsula Medical School, University of Plymouth, UK

b General Practitioner, Box Surgery, Wiltshire; Honorary Lecturer, University of Bath; COPD Lead, Royal College of General Practitioners, UK Senior Clinical Research Fellow, Allergy and Respiratory Research Group, Centre for Population Health Sciences: GP Section, The University of Edinburgh, Scotland, UK

d BLF Respiratory Nurse Specialist, Bristol Community Health, UK

e Lead Nurse / Advanced Nurse Practitioner, Collingwood Health Group, North Shields, UK

Respiratory Nurse Consultant, University Hospitals of Leicester; Respiratory Clinical Lead, East Midlands Strategic Health Authority, England, UK Senior Lecturer, Division of Health and Social Care Research, Department of Primary Care and Public Health Sciences, Kings College, London, UK General Practitioner, Shepton Mallet; Education Lead, PCRS-UK; Associate Postgraduate Dean, Severn Deanery, UK

Received 8th April 2010; revised version received 20th July 2010; accepted 3rd October 2010

\begin{abstract}
The Consultation on a Strategy for Services for COPD in England is the culmination of five years' work by respiratory specialists from all disciplines, as well as representatives from the voluntary sector, patients, carers and planners. It has been led by the Department of Health in England and the joint National Directors for the programme, Professor Sue Hill and Dr Robert Winter. The Strategy outlines service standards for providers of COPD care and is complementary to the UK National Institute for Health and Clinical Excellence (NICE) guidelines on the management of COPD. Its key elements are:

- $\quad$ preventing the development and progression of COPD

- diagnosing COPD accurately and at an early stage

- developing structured care based on national guidance

- promoting self-management education

- $\quad$ reducing the number of people admitted to hospital

- improving access to end-of-life care

- $\quad$ promoting good asthma services.

In essence this is an aspirational strategy which aims to change the way that the NHS in England delivers care for people with COPD by identifying them earlier and managing them optimally in order to reduce the likelihood of progression to the more severe stages of the disease. An economic impact assessment shows that implementing the Strategy will save approximately $\mathrm{f} 1$ billion over 10 years as well as sparing many people from a debilitating illness.

This supplement is based on the Strategy Consultation document as well as the NICE guidelines for COPD management. It aims to elucidate practical implementation of the COPD Strategy, and includes verbatim the Strategy recommendations as well as highly relevant clinical information from the NICE guidelines. Implementation of the Strategy recommendations should lead to optimum care for patients with COPD.

(C) 2010 Primary Care Respiratory Society UK. All rights reserved.

R Jones et al. Prim Care Resp J 2010;19(Suppl 2): S1-S17

doi:10.4104/pcrj.2010.00081
\end{abstract}

Keywords: COPD, Strategy, services, England, Department of Health, prevention, diagnosis, case-finding, treatment, chronic care, self-management, exacerbations, end-of-life care, implementation

\footnotetext{
* Corresponding author: Dr Rupert Jones, Department of Primary Care, Peninsula Medical School, 1 Davy Road, Plymouth, UK Tel: +44 (0)1752 764293 Fax: +44 (0)1752 764259 E-mail: rupert.jones@pms.ac.uk
} 


\section{Contents}

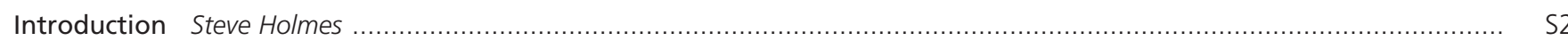

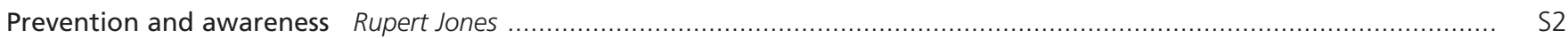

Identification and diagnosis Rupert Jones and Judith Lawrence ........................................................................ S3

COPD management: chronic ongoing care Kevin Gruffydd-Jones and Rupert Jones …............................................ S7

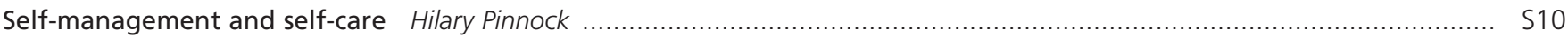

Management of acute exacerbations Kevin Gruffydd-Jones and Sarah-Jane Peffers ................................................... S11

End-of-life care Patrick White and Jane Scullion ......................................................................................... S13

Implementing the Strategy for COPD Services in England, measuring outcomes, and commissioning care $\quad$ Rupert Jones ...... S14

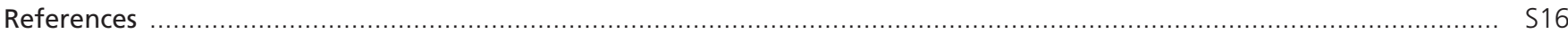

\section{Introduction}

Steve Holmes

Chronic obstructive pulmonary disease (COPD) is currently the sixth largest cause of death worldwide and is anticipated to be the third commonest cause of death by $2020 .{ }^{1}$ It is also the second commonest reason for emergency hospital admission in the UK, accounting for 27,000 admissions per year. ${ }^{2}$ There is now increased awareness of significant numbers of undiagnosed patients, ${ }^{3}$ and of the wide variation in the quality of care provided..$^{1,4,5}$ COPD-related healthcare costs are a significant proportion of any country's economy, ${ }^{4}$ and cost effective use of resources is now increasingly important. ${ }^{6}$

Following a report from England's Chief Medical Officer in 2005, ${ }^{7}$ the Department of Health (DOH) in England has been developing a National Strategy to enhance the care of patients with COPD. This has required a structured process using expertise from many areas of the respiratory community - emphasising the importance of transcending traditional primary/secondary care boundaries - and the UK Primary Care Respiratory Society (PCRS-UK) has been involved throughout. ${ }^{8}$

The Consultation on a Strategy for Services for COPD in England has now been published. ${ }^{9}$ This will clearly need to link with other national policy, and a UK government White Paper published in July 2010 is anticipated to have far-reaching consequences on the structure and methods of commissioning of services within the UK National Health Service (NHS). ${ }^{10}$ The Consultation document ${ }^{9}$ also links with the recently published 2010 update on COPD management from the UK National Institute for Health and Clinical Effectiveness (NICE). ${ }^{11}$

This article covers the key areas identified in the Consultation document;

- prevention, awareness and identification of COPD

- diagnosis and differentiation from asthma and other respiratory diseases

- high quality acute and chronic care

- self-management

- end-of-life care

- implementation

The importance of smoking cessation ${ }^{7.12-14}$ is emphasised, as is the fact that more needs to be done to inform the population about COPD and its implications. ${ }^{3}$ The presence of "missing millions" with undiagnosed COPD requires improved case-finding and possibly screening, ${ }^{15,16}$ as well as quality diagnostic spirometry to complement clinical assessment. ${ }^{8,17-21}$ There is a gap between ideal and provided care, and wide variation in provision across all areas of the health service, ${ }^{21}$ which the Strategy attempts to address. Finally, there is emphasis on the importance of end-of-life care for patients with COPD.

Implementation of the Strategy for COPD services in England across all areas of the health service will be crucial, and the publication of this PCRJ supplement, following publication of the Consultation document, ${ }^{9}$ is part of the implementation process. The 24 Key Recommendations of the Strategy are highlighted throughout the text. In order to increase relevance to practising clinicians, where appropriate there is clinical content based largely on the 2010 NICE guideline. ${ }^{11}$ The PCRS-UK has also published an online Quick Reference Guide ${ }^{22}$ summarising the Strategy Consultation document.

The Strategy for COPD services in England has widespread applicability. If the Strategy achieves its aims, it should stimulate improved quality of care for COPD patients for many years to come.

\section{Prevention and awareness \\ Rupert Jones}

Recommendation 1: Work should be undertaken locally to identify where prevalence is high, and planned interventions should be developed to encourage behaviour change and help to minimise inequalities.

The stark statistics in the Consultation on a Strategy for COPD Services in England ${ }^{9}$ show that COPD affects 2.8 million people with only $0.8 \mathrm{~m}$ diagnosed. COPD costs the UK NHS $f 1$ billion, it causes 1 in 8 emergency admissions, 30\% are readmitted soon after, and it accounts for at least $5 \%$ of all deaths in England and Wales (24,800 in 2008) and is a contributor to many more. The burden is growing, especially in women; more women die of COPD than from breast cancer. ${ }^{23}$ COPD is more common in lower socio-economic groups and interacts with other conditions - for example, for every $10 \%$ decrease in $\mathrm{FEV}_{1}$, cardiovascular events and deaths increase by $20 \%$ and $28 \%$, respectively. ${ }^{24}$

Notwithstanding this, $89 \%$ of the UK population have not heard of COPD. The Strategy aims to raise awareness in the population and emphasise the causes of COPD and the fact that COPD is both treatable and preventable. 
Recommendation 2: The importance of lung health should be understood and people should take appropriate action to maintain good lung health.

Prevention policies need to start in pregnancy, through childhood and onwards (see Figure 1). There is potential to prevent COPD by people adopting healthy lung behaviours such as avoiding cigarette smoke, occupational and other harmful exposures. Many people develop major lung damage without symptoms and this group may be difficult to identify. Others do have symptoms without seeking help - they may have breathlessness on exertion which they attribute to ageing, and a cough which they attribute to smoking. These people, who are at risk of COPD, need to be encouraged to seek an assessment of their lungs. This can be done by proactive means (case-finding) or opportunistically (using existing healthcare interventions such as smoking cessation programmes).

Recommendation 3: The consequences of exposure to the main risk factors of COPD should be understood and people with early symptoms of lung disease need to be able to recognise their symptoms and seek further investigation.

The roots of the disease start in utero and in childhood, when factors such as atopy, passive smoking and respiratory infections may be as important as conventional risk factors such as smoking. ${ }^{25}$ There is a strong relationship between lifelong cigarette exposure in pack years and the chance of developing COPD. ${ }^{26}$ Approximately half of those with COPD are current smokers, and these patients report that $8 \%$ have not been told to stop and a third have not been offered treatment or referral to smoking cessation clinics. ${ }^{27}$ Effective therapies exist especially when part of a structured smoking cessation programme supported by medication - for example, varenicline improves quit rates fourfold in people with COPD. ${ }^{28}$

Recommendation 4: Further evaluation work should be undertaken on the impact of the use of lung age tests on individuals' motivation for smoking cessation and testing for lung disease as a case-finding approach.

The Strategy External Reference Group recommended consideration of a lung health check in children and young adults at ages 7 and 14, and in adults at ages 25 and 40 years. ${ }^{8}$ In adults, increased use of case-finding spirometry and questionnaires may promote earlier detection of COPD. ${ }^{16}$

Such screening and case-finding programmes will have significant resource implications, and will therefore be tested by the National Screening Committee and also, where appropriate, in primary care pilots to assess feasibility, efficacy and cost benefit. The aim is to:

- test lung function in these age groups and identify those at risk of future problems

- ask about respiratory symptoms and take necessary steps

- identify risk factors and educate to change future risks.

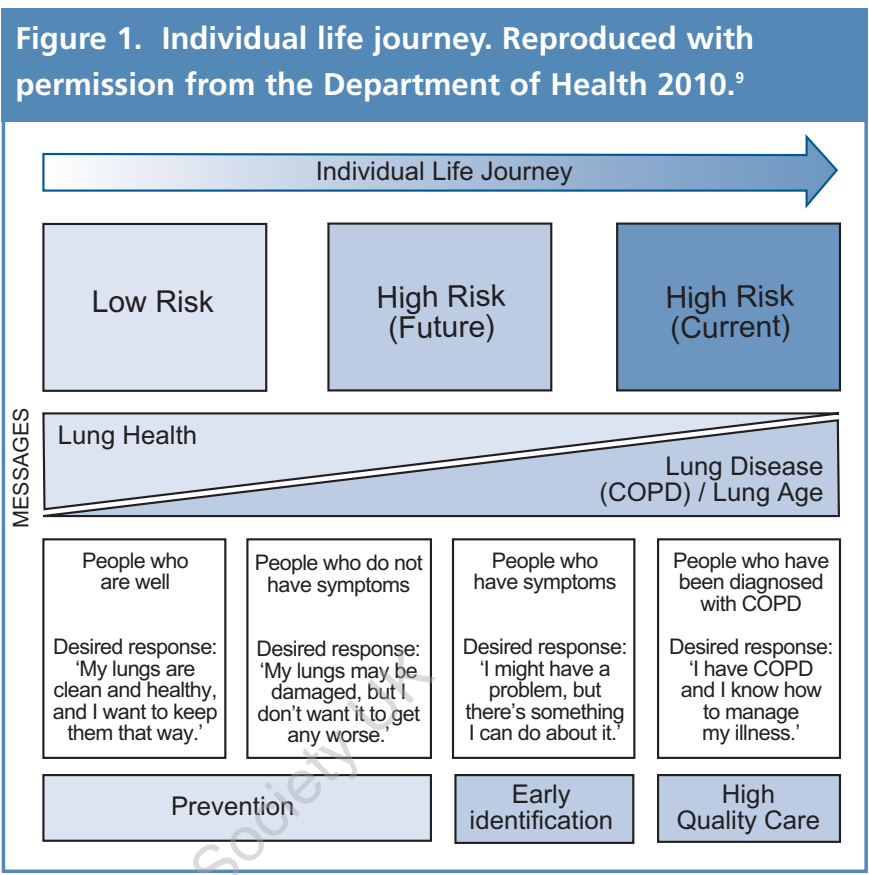

Recommendation 5: Employers should look to minimise the risks of workforce exposure to known risk factors and work with partners from health and social care to support people with COPD to manage their condition and remain in work.

The Consultation document specifically aims to raise awareness of symptoms for those at risk, and to encourage individuals to adopt strategies to prevent or ameliorate future health problems. ${ }^{9}$ By promoting the concept of lung health and symptomatology, the Strategy should provide an opportunity to identify COPD earlier.

\section{Identification and diagnosis}

Rupert Jones and Judith Lawrence

Fundamental to the Consultation on a Strategy for Services for COPD in England is the early identification and diagnosis of those individuals at risk. Its success will be influenced by the ability of health care professionals to collaborate with other care providers to meet the needs of the patient.

Focusing on identification and diagnosis, the Consultation document ${ }^{9}$ proposes several key areas for targeting resources:

- Early identification

- Accurate quality-assured diagnosis

- Spirometry assessment in COPD

- Disease Registers

- Information

There needs to be a multifaceted approach to identification and diagnosis:

- People need to be aware of the symptoms of lung disease and when to seek assessment and advice from health care professionals 
R Jones et al.

Figure 2. Differentiating asthma from COPD. Reproduced with permission from the National Institute of Health and Clinical Excellence. ${ }^{11}$

\begin{tabular}{|l|l|l|}
\hline Clinical features differentiating COPD and asthma & COPD & Asthma \\
\hline Smoker or ex-smoker & Nearly all & Possibly \\
\hline Symptoms under age 35 & Rare & Often \\
\hline Chronic productive cough & Common & Uncommon \\
\hline Breathlessness & Persistent and progressive & Variable \\
\hline Night time waking with breathlessness and/or wheeze & Uncommon & Common \\
\hline Significant diurnal or day to day variability of symptoms & Uncommon & Common \\
\hline
\end{tabular}

- Health care professionals must be competent in the assessment and diagnosis of COPD, a fundamental ability being the ability to take an accurate history.

- Health care professionals must be able to differentiate between COPD and other respiratory diseases such as asthma to ensure that the patient is offered optimum care (see Figure 2).

Recommendation 23: The NHS should recognise similarities and differences between asthma and COPD, and should commission services accordingly to optimise the model of provision of care

Recommendation 10: Disease registers should be accurate and used to improve COPD outcomes.

- Competent assessment of disease severity should be based on a number of features, not just one entity or test, to ascertain disability and prognosis.

- Disease registers must be accurate and up to date to ensure regular review of diagnosed patients, managing care and targeting resources.

- Quality information obtained at assessment must be recorded accurately

Recommendation 6: Healthcare professionals should understand the risk factors for COPD and offer advice or an appropriate intervention to those who are at risk.

Health care professionals should understand the risk factors for COPD and be able to identify those at risk (see Table 1), offer them appropriate education to prevent the disease developing, and assess patients' lungs to establish the presence of lung disease and its cause.

While COPD presents in adults, failure of adequate lung development or damage in childhood reduces pulmonary reserves and puts individuals at an increased risk of developing symptomatic lung disease later in life..$^{25}$ In adults, lung damage occurs without symptoms, so warning people of the causes of

\section{Table 1. Risk factors for developing COPD.}

Risk factors that affect children

- $\quad$ Alpha-1-antitrypsin deficiency

- $\quad$ Smoking in pregnancy

- Low birth weight

- $\quad$ Severe viral and other infections in infancy

- Asthma and wheezing in childhood

- Environmental pollution (including cigarette smoke)

- Smoking in childhood

- Childhood deprivation, poor nutrition including obesity

Risk factors for adults

- $\quad$ Smoking

- Occupation

- Environment and family history

- Health events in childhood

- $\quad$ Genetic susceptibility

lung disease allows them to change their lifestyle before permanent serious damage accrues. By the time someone is breathless with COPD, much irreversible damage is done and the lungs will only get worse with time.

There is insufficient evidence, as yet, for widespread screening, and the case for lung health checks in children and adults aged 25 and $40^{8}$ is being assessed in research projects. However, it may be useful to consider the risks throughout people's lives so they can be made aware of positive steps to take to keep their lungs healthy.

\section{Target groups for COPD identification}

In practice, widespread screening in asymptomatic people is not yet required. Screening or case-identification of at-risk groups can be performed using symptom-based questionnaires ${ }^{29,30}$ or the measurement of airflow obstruction such as case-finding spirometry. Practices should be prepared to check people in the following groups:

\section{First priority}

Smokers over the age of 40 with:

- >20 pack-year smoking history 
- Frequent courses of antibiotics and/or inhaled medication

- Chronic cough

- Breathlessness

- On existing asthma registers

Then: All smokers over the age of 40

Then: Individuals over the age of 40 and any of the following characteristics:

- Ex-smoker

- Previous pulmonary tuberculosis

- First-degree relative of those with COPD

- Known occupational or environmental exposure (coal mining, exposure to wood burning stoves)

Once identified, the risk factors and symptoms should be documented and spirometry performed with other tests as appropriate to diagnose the underlying lung condition(s).

Whilst the Consultation document recommends assessing patients over 40, ${ }^{9}$ NICE suggests a lower limit of age 35 and above. ${ }^{11}$

\section{Diagnosing COPD}

Recommendation 8: A diagnosis of COPD should be confirmed by quality assured spirometry and other investigations appropriate to the individual.

The definition of COPD in the Consultation on a Strategy for Services for COPD in England ${ }^{9}$ follows the recommendations from GOLD ${ }^{31}$ and the 2010 NICE revision. ${ }^{11}$ The diagnosis requires high quality post-bronchodilator spirometry combined with clinical assessment and exclusion of other diagnoses. Currently, the standards of spirometry performance and interpretation are a cause for concern throughout primary care, and to a lesser extent in secondary care. ${ }^{15,17}$ Furthermore, audit data suggest that $27 \%$ of those on COPD registers do not meet the diagnostic criteria for COPD, while failure to use post-bronchodilator spirometry may result in severity being overestimated in $18 \% .^{32}$

A diagnostic algorithm is shown in Figure 3.

Problems identified with providing accurate spirometry include: ${ }^{17}$

- Inappropriate equipment

- Lack of calibration

- Inadequate training on conduct and quality checks

- Inadequate support

- Problems interpreting the result

The Strategy requires that quality-assured diagnostic standard spirometry is required to make the diagnosis of COPD and assess disease severity, and the current recommendations ${ }^{17}$ include the following:

\section{The spirometer:}

- should be able to record the parameters of forced expiratory volume in one second $\left(F E V_{1}\right)$, forced vital capacity (FVC), the $\mathrm{FEV}_{1} / \mathrm{FVC}$ ratio, and display a graph of volume against time.

- should be calibrated before use

The spirometrist should be trained:

- in its use and calibration
Figure 3. COPD diagnostic algorithm (adapted from NICE with permission $\left.{ }^{11}\right)$.

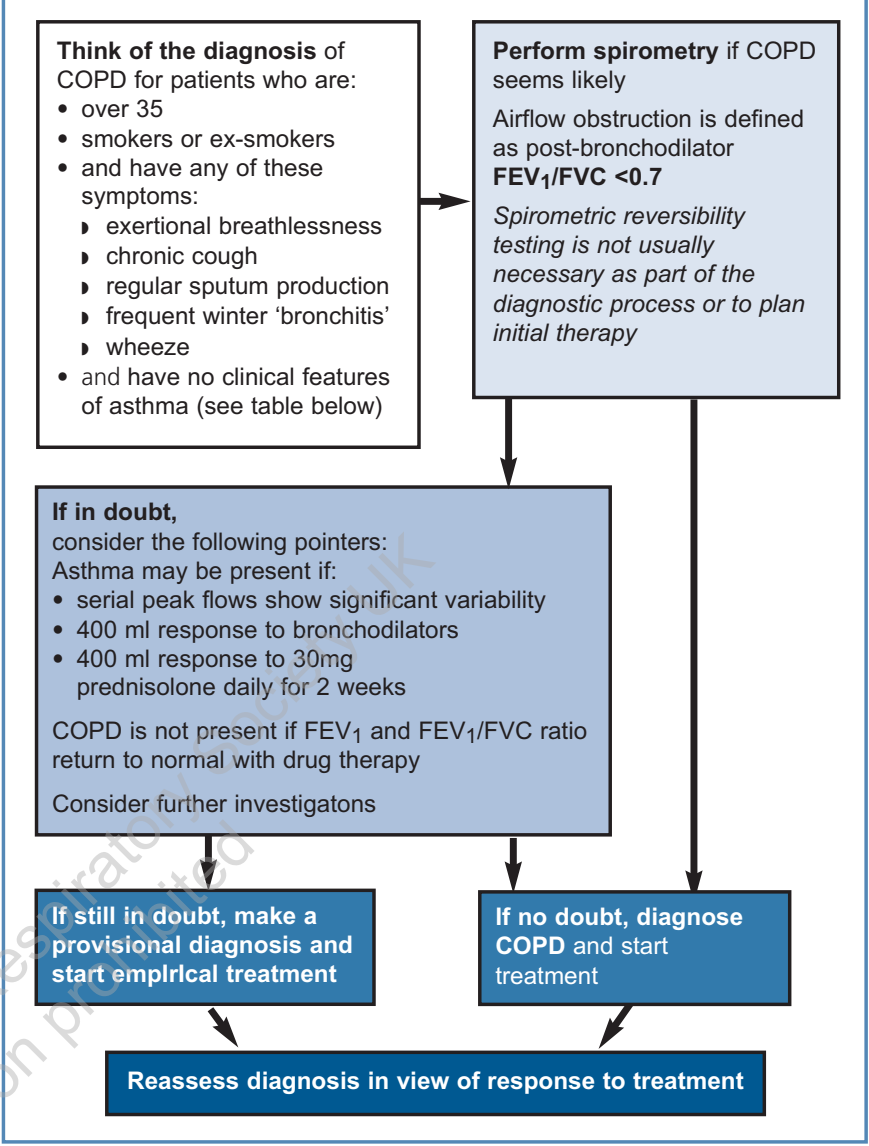

- in how to spot faults such as slow start, extra breaths etc.

- to understand the preparation of the patient for various types of spirometric assessment

- to understand which readings are required in different clinical scenarios such as reversibility testing or when to use the slow vital capacity

Whoever interprets the spirometry results to make the diagnosis must be able to calculate the following (see Table 2):

- $\mathrm{FEV}_{1}$

- FVC

- $\mathrm{FEV}_{1} \%$ predicted

- the ratio of FEV 1 to VC (highest of FVC or SVC)

Anyone performing diagnostic standard spirometry should undertake quality-assessed, certified and approved training. With regard to case-finding spirometry, any form of spirometry not meeting diagnostic standards as outlined above should be considered as "case-finding". ${ }^{18}$ Case-finding spirometry may be performed using hand-held or screening devices used for detecting airflow obstruction, though the Strategy Consultation document has recommended further research.

For post-bronchodilator readings it is not necessary to stop treatment prior to the test. Post-bronchodilator tests are needed for the diagnosis in the majority of cases and for monitoring 


\begin{tabular}{l} 
Table 2. Classification of airflow obstruction severity according to various guidelines. Reproduced with permission from \\
the National Institute for Health and Clinical Excellence. ${ }^{11}$ \\
\cline { 3 - 6 }
\end{tabular}

*Symptoms should be present to diagnose COPD in people with mild airflow obstruction ** Or FEV $1<50 \%$ with respiratory failure.

people with diagnosed COPD.

For reversibility testing drugs have to be stopped well in advance. Reversibility testing is needed in a minority of cases to differentiate the causes of airflow obstruction - e.g. differentiating asthma from COPD. ${ }^{11}$

Establishing a spirometry service is key to achieving the aims of the Strategy. The Consultation document does not define who should do spirometry or where it should be done, but does require the person to have the right competencies. ${ }^{9}$ A variety of models include a 'hub and spoke' system whereby a team of experts in the centre (or 'hub') is able to train, assess and support those performing spirometry in practice (the 'spokes'), and these various models are being tested as part of the work being undertaken with NHS Improvement.

\section{Assessment of severity in COPD}

Recommendation 9: An assessment of the severity and presence of co-morbid conditions should be made at the point of initial diagnosis, and at least every three years.

No single measure can assess the severity of COPD accurately. ${ }^{11}$ For this reason, healthcare professionals should use a variety of prognostic indicators in order to guide practice and plan appropriate care. Disability and $\mathrm{FEV}_{1}$ do not always correlate, and therefore $\mathrm{FEV}_{1}$ should not be used in isolation. The following prognostic factors should be used to formulate a more holistic view of the patient's overall wellbeing:

- $\mathrm{FEV}_{1}$

- Breathlessness (MRC scale)

- Health status

- Exercise capacity (6-minute walk test)

- BMI

- Presence of cor pulmonale

- Presence of respiratory failure using pulse oximetry or arterial blood gas analysis

- Carbon monoxide transfer factor (TLCO)

- Presence of co-morbidities

$\mathrm{NICE}^{11}$ recommends using the BODE index, ${ }^{33}$ [Body Mass Index, Degree of Airflow Obstruction expressed as $\mathrm{FEV}_{1} \%$ predicted, Dyspnoea (MRC Dyspnoea score), and Exercise indicator limitation (6-minute walking test)], a multidimensional grading system. The BODE index is better than the $\mathrm{FEV}_{1}$ at predicting the risk of death from any cause and from respiratory causes among patients with COPD. ${ }^{11}$ However, a 6-minute walking test is required which can be difficult to undertake in primary care. More recently validated alternatives are the DOSE ${ }^{34}$ (Dyspnoea, Airways Obstruction, Smoking Status, Exacerbation) and $A D O^{35}$ indexes. However, there was insufficient evidence yet for these to be recommended by NICE. ${ }^{11}$

The 2010 NICE guideline ${ }^{11}$ on severity classification of airflow obstruction (which should not be equated with 'disease' severity) is in line with the recommendations by GOLD ${ }^{31}$ and the ATS/ERS ${ }^{37}$ (see Table 2). NICE suggests that asymptomatic patients with GOLD stage $1\left(\mathrm{FEV}_{1}>80 \%\right.$ and $\mathrm{FEV}_{1} / \mathrm{FVC}$ ratio $\left.<0.7\right)$ should not be considered as suffering respiratory disease, but symptomatic patients with GOLD stage 1 have worse health status, and higher rates of $\mathrm{FEV}_{1}$ decline and health care consumption. ${ }^{38}$

\section{Confirming the diagnosis}

There is no single test to diagnose COPD. Once diagnostic standard post-bronchodilator spirometry has confirmed airflow obstruction, the diagnosis should be confirmed by;

(i) excluding other causes - e.g. bronchiectasis or tumour, and (ii) establishing that the patient has appropriate clinical features.

A full description of the clinical features of COPD and related respiratory illness such as asthma are outside the remit of this paper, but details are summarised in the NICE COPD guideline (see Table $3)^{11}$ and national ${ }^{39}$ and international ${ }^{40}$ asthma guidelines.

Recommendation 7: In line with WHO advice, all people with a diagnosis of COPD and/or a history of adult asthma should be assessed for alpha-1-antitrypsin deficiency.

All patients with COPD should have a chest radiograph (CXR). An alpha-1-antitrypsin blood test is recommended for all COPD patients by the World Health Organisation and the Consultation document, ${ }^{9}$ but NICE 2010 suggests that testing should only occur if there is early onset, minimal smoking history or a family history. ${ }^{11}$

Where the diagnosis is in doubt or symptoms are atypical (for 


\begin{tabular}{ll}
$\begin{array}{l}\text { Table 3. Clinical Features of COPD (adapted from NICE } \\
\text { with permission }{ }^{11} \text { ). }\end{array}$ & Signs \\
\hline Symptoms & Hyperinflated chest \\
\hline Exertional breathlessness & Wheeze or quiet breath sounds \\
\hline Chronic cough & Purse lip breathing \\
\hline Regular sputum production & Use of accessory muscles \\
\hline Frequent winter "bronchitis" & Paradoxical movement of lower ribs \\
\hline Wheeze & Reduced crico-sternal distance \\
\hline Exertional breathlessness
\end{tabular}

example, disproportionate breathlessness) referral for further investigation may be required.

Patients with confirmed COPD should be entered on the disease register and assessed for disease severity including:

- Lung function (FEV $1 \%$ predicted)

- Breathlessness (MRC dyspnoea scale)

- Exacerbation frequency

- Smoking status

- Body mass index

- Important co-morbid conditions

The Strategy Consultation document also suggests recording a measure of health status - for example, the COPD assessment test ('CAT' - see http://www.catestonline.org). ${ }^{41}$

\section{COPD management: chronic ongoing care} Kevin Gruffydd-Jones and Rupert Jones

This section of the Strategy Consultation document ${ }^{9}$ emphasises moving away from current models of purely reactive management (such as control of symptoms and management of acute exacerbations) towards a system of proactive care involving minimising the future risk of exacerbations and hospital admissions, and slowing disease progression.

\section{Adapting the chronic care model for COPD}

The chronic care model of Wagner ${ }^{42}$ has identified four essential elements in structured care likely to have a major impact on the quality, effectiveness and efficiency of care:

- provision of a comprehensive system to support clinical management

- promotion of self-management and adoption of a healthy lifestyle

- evidence-based support for decision making

- use of Clinical guidelines.

Recommendation 12: Chronic disease management approaches should be adopted in health and social care for all people diagnosed with COPD, irrespective of severity or symptoms

\section{Clinical Networks}

An important factor in the implementation of the Strategy will be the development of local Clinical Networks bringing together primary and secondary health care professionals, managers and patients, to commission, provide and support COPD services in a locality. These will be supported at Strategic Health Authority (SHA) level by COPD Clinical leads.

\section{Assessment and Review}

One of the key elements of proactive COPD management is proper assessment at the time of diagnosis followed by regular structured review.

\section{Assessing severity}

Traditionally the severity of disease has been linked to the degree of airflow obstruction. The 2004 NICE Guideline ${ }^{36}$ criteria for severity of airflow obstruction has recently been updated ${ }^{11}$ in line with the GOLD criteria ${ }^{31}$ (see Table 2).

However, the degree of airflow obstruction correlates poorly with quality of life and exercise limitation, and therefore disease severity should be assessed in conjunction with other patientcentred markers of disease activity such as dyspnoea scores, health status, and frequency of exacerbations.

Multi-dimensional assessment tools have been developed. The BODE index ${ }^{33}$ assesses disease severity by various measurements and is seen as an evidence-based prognostic indicator. Other more primary care-friendly indices have been developed (DOSE ${ }^{34}$ and ADO $^{35}$ ).

\section{Frequency of review}

It is recommended that proactive review be carried out at intervals according to disease severity. For example, a patient with stable mild disease (FEV $170 \%$ predicted, MRC score 2, no exacerbations) can be reviewed annually, whilst a patient with more severe disease (FEV $140 \%$ predicted, MRC score 4, and more than one exacerbation per year) might be reviewed 6-monthly and after each exacerbation (especially after admission).

There is considerable interest in Patient-Reported Outcome Measures (PROMS) which measure the impact of the disease on the patient, especially in terms of quality of life. There are several selfcompleted questionnaires available which measure this and these are being piloted by the $\mathrm{DOH}$. There is particular interest in the 8question patient-completed COPD assessment test (CAT) ${ }^{41}$ which can be completed quickly by patients as part of a COPD review, providing information on the impact of COPD on their health.

\section{Elements of a regular clinical review}

A patient on the COPD register requires regular clinical review in order to:

- Assess the impact of the disease upon the patient in terms of symptoms, functional limitation, quality of life, psychological and social factors, exacerbations, lung function and hypoxaemia.

- Promote self-management by education, health promotion (including giving up smoking) and use of individualised action plans where appropriate.

- Review the need for, efficacy of, and safety of, pharmacological and non-pharmacological interventions (including inhaler technique) 
R Jones et al.

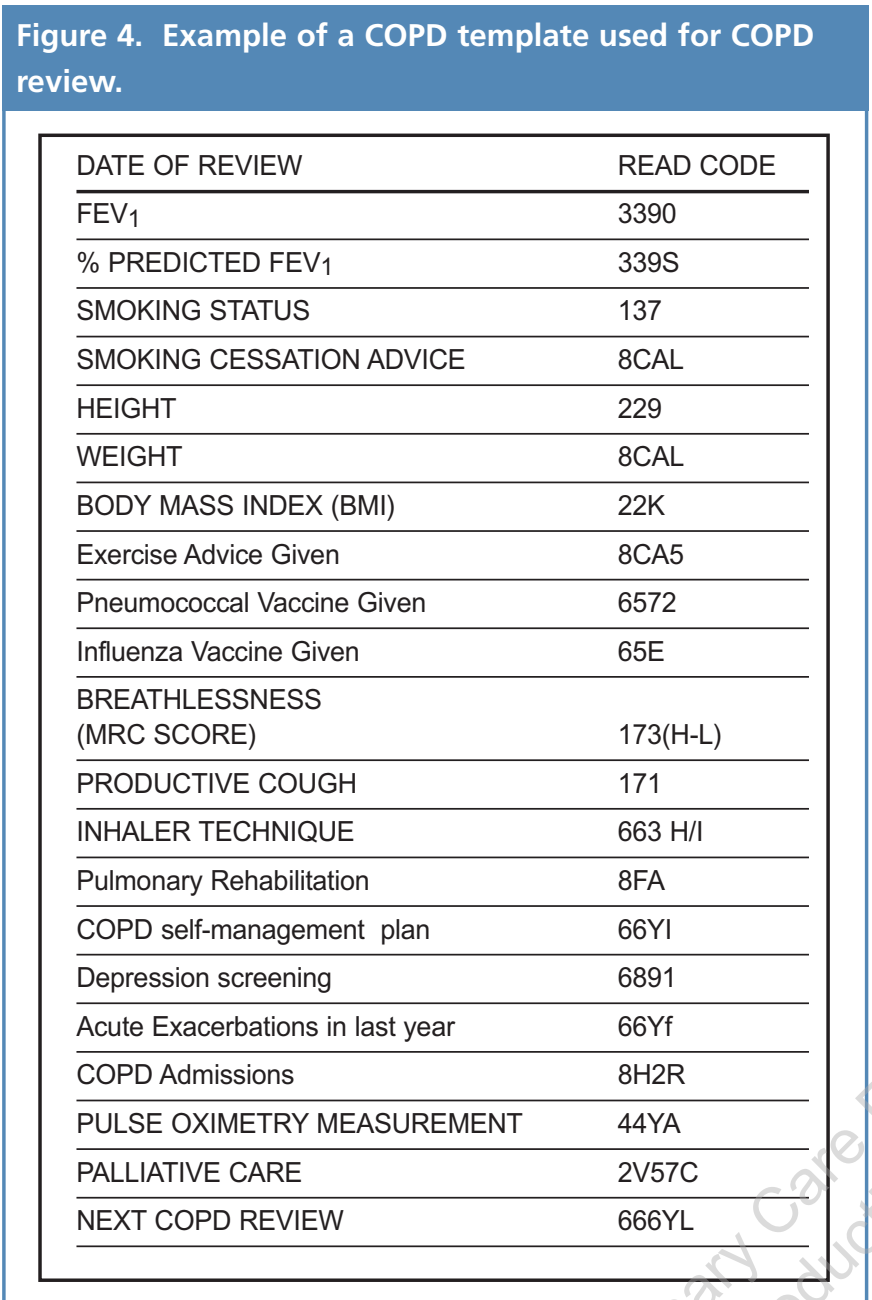

- Identify co-morbid conditions and the emergence of complicating associated conditions such as lung cancer or bronchiectasis

- Consider the need for specialist respiratory referral including oxygen assessment and palliative care

Figure 4 shows an example of a COPD review template used in a primary care setting (including Read Codes). Additional entries might be added for co-morbidities such as diabetes or osteoporosis, or to include social factors such as the needs of carers.

\section{Evidence-based treatment and management}

Recommendation 24: People should be managed according to evidence-based guidelines

Recommendation 13: All people with COPD should receive evidence-based treatment using a structured medicines management approach

In line with the Chronic Care model, ${ }^{42}$ treatment of the individual patient is driven by clinical guidelines - in this case, the NICE 2010 Guidelines. ${ }^{11}$ The PCRS-UK has adapted the NICE guidelines for use in primary care (Figure 5$)^{43}$ and specific details of the use of inhaled treatments are shown in Figure 6.11 A separate medicines management guide will be published looking at ways of safe and cost effective ways of prescribing and using medicines for people with COPD.

\section{Non-pharmacological interventions}

The Consultation document emphasises the following nonpharmacological interventions: ${ }^{9}$

\section{Smoking cessation}

Figure 5. Management of Stable COPD in primary care. ${ }^{43}$

\begin{tabular}{|c|c|c|c|c|}
\hline \multicolumn{3}{|c|}{$\begin{array}{l}\text { ALL PATIENTS } \\
\text { Smoking cessation advice } \\
\text { Patient education / self management } \\
\text { Assess co-morbidity } \\
\text { ASSESS BMI: Dietary Advice if BMI >25 }\end{array}$} & \multicolumn{2}{|c|}{$\begin{array}{l}\text { Exercise promotion } \\
\text { Pneumococcal vaccination } \\
\text { Annual influenza vaccination } \\
\text { Specialist dietary referral if } \mathrm{BMI}<20\end{array}$} \\
\hline $\begin{array}{c}\text { SYMPTOMS? } \\
\text { Breathlessness } \\
\text { Short-acting } \\
\text { bronchodilators } \\
\text { (B-agonist/antimuscarinic) } \\
\text { for relief of symptoms }\end{array}$ & $\begin{array}{c}\text { FUNCTIONAL } \\
\text { LIMITATION? } \\
\text { MRC score } \geq 3 \\
\text { Optimise } \\
\text { pharmacotherapy } \\
\text { (See algorithm) } \\
\text { Offer pulmonary } \\
\text { rehabilitation } \\
\text { Screen for } \\
\text { anxiety/depression }\end{array}$ & $\begin{array}{l}\text { EXACERBATIONS } \\
\text { (Oral steroids/ } \\
\text { antibiotics/ } \\
\text { hospital } \\
\text { admissions) } \\
\text { Optimise } \\
\text { pharmacologic } \\
\text { therapy } \\
\text { Discuss action plans } \\
\text { including use of standby } \\
\text { oral steroids and } \\
\text { antibiotics }\end{array}$ & $\begin{array}{l}\text { HYPOXIA? } \\
\text { Oxygen } \\
\text { saturation } \leq 92 \% \\
\text { at rest in air } \\
\begin{array}{l}\mathrm{FEV}_{1}<30 \% \\
\text { predicted }\end{array}\end{array}$ & $\begin{array}{l}\text { HOLISTIC CARE } \\
\text { Check social support } \\
\text { (e.g. carers } \\
\text { and benefits) } \\
\text { Treat } \\
\text { co-morbidities } \\
\\
\text { Consider palliative } \\
\text { therapy or secondary } \\
\text { care referral for } \\
\text { resistant symptoms } \\
\\
\text { Refer to specialist } \\
\text { palliative care teams } \\
\text { for end-of-life care }\end{array}$ \\
\hline
\end{tabular}




\section{Figure 6. Inhaled pharmacotheray algorithm (adapted from NICE with permission $\left.{ }^{11}\right)$.}

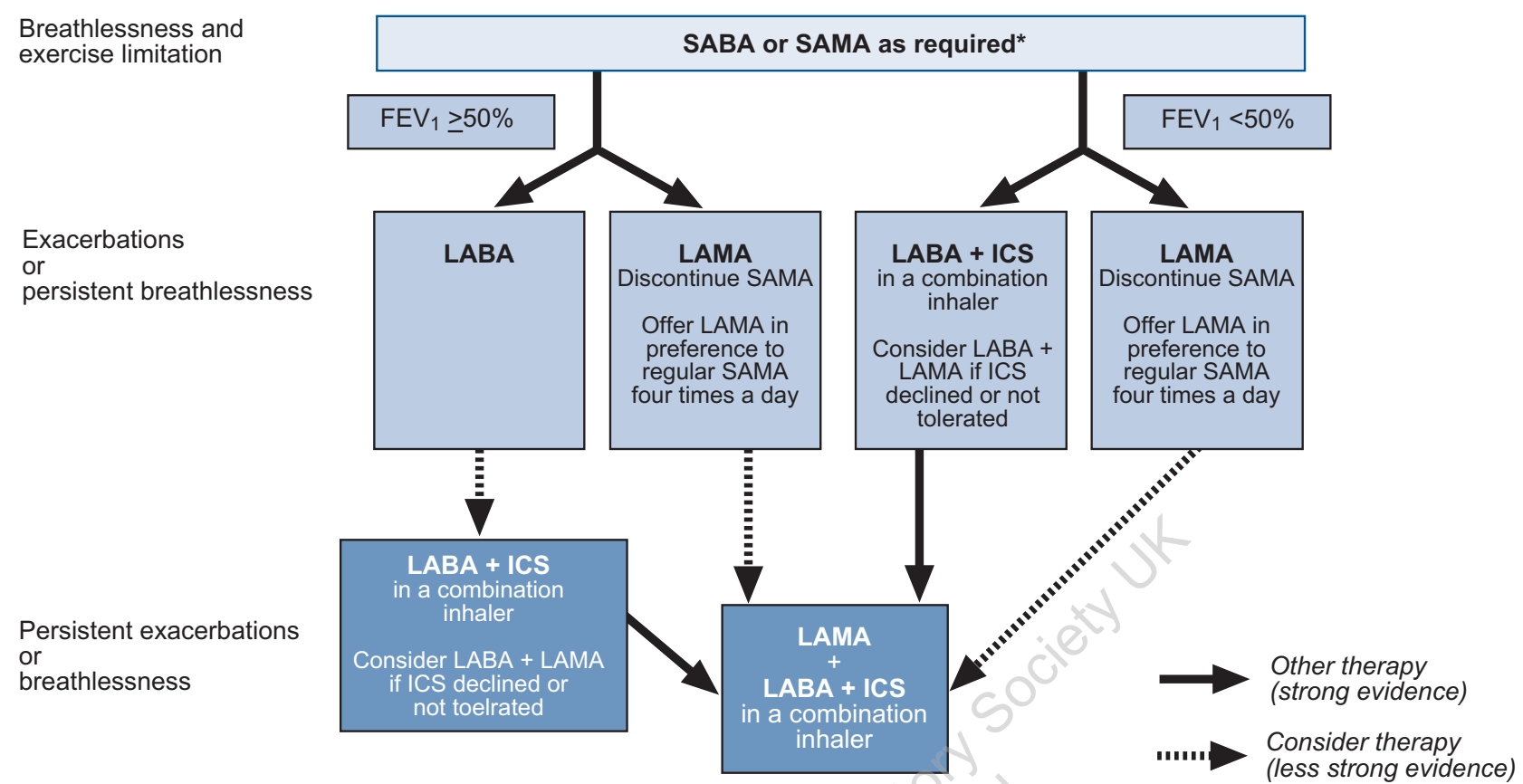

SABA: short-acting $\beta_{2}$-agonist; SAMA: short-acting muscarinic antagonist; LABA: long-acting $\beta_{2}$-agonist; LAMA: long-acting muscarinic antagonist; ICS: inhaled corticosteroid *SABA (as required) may continue at all stages

Recommendation 13 (cont:) A step-up approach to smoking cessation intervention as part of preventive management strategies should be taken.

Smoking status should be checked at every COPD review. Brief advice and then regular input to aid quitting should be given to those continuing to struggle against their tobacco dependence. ${ }^{44}$

\section{Oxygen}

Recommendation 14. All people with COPD and hypoxaemia should be clinically assessed for long-term oxygen therapy and reviewed at regular intervals, and existing home oxygen registers should be reviewed.

The provision of home oxygen is a major financial burden on the NHS (approximately $\mathrm{f} 110$ million per annum in England). Oxygen prescribing for patients with COPD is poorly monitored and may be inappropriate. Oxygen should only be provided for those who have demonstrable hypoxia, it is potentially toxic, and patients should be assessed before it is prescribed. There is no evidence to support the use of short burst therapy for symptomatic relief of breathlessness. However, there is strong evidence that long-term oxygen therapy ( $\geq 15$ hours per day) for patients with persistent and profound hypoxia reduces mortality.

In primary care, patients with oxygen saturations persistently $\leq 92 \%$ on air when free from an exacerbation should be referred to oxygen assessment services. Ambulatory oxygen may be helpful to a minority of patients with exercise desaturation but should only be prescribed after a specialist assessment. Once home oxygen is prescribed then the patient should be placed on a home oxygen register and regularly reviewed.

\section{Exercise and pulmonary rehabilitation}

Recommendation 15: All people with COPD should be advised to undertake moderate exercise according to their condition. People with functional impairment should be referred for quality assured pulmonary rehabilitation.

People with COPD, irrespective of severity, become physically deconditioned due to muscle weakness and loss of cardiovascular fitness. Exercise is a vital part of COPD treatment.

Those with mild COPD (MRC dyspnoea score 1 or 2) can increase physical fitness by taking regular exercise in chunks of variable duration but this should total 150 minutes per week. Many localities run generic exercise promotion schemes which may be helpful. Housebound patients (MRC dyspnoea score 5) may benefit from home-based physiotherapy programmes.

One of the most cost-effective interventions for patients with COPD is pulmonary rehabilitation, a multi-disciplinary holistic intervention aimed at people with COPD who are functionally impaired but usually not housebound (i.e. MRC dyspnoea score 3 or 4$)$

Key features of pulmonary rehabilitation are:

- Supervised exercise training with education tailored to promote self management skills.

- Multidisciplinary input e.g. provided by physiotherapists/ 
doctors/ nurses/nutritionist/psychologist

- It can be provided in hospitals or in the community

- A programme is typically run for 6-12 weeks.

There is strong evidence that pulmonary rehabilitation can improve exercise tolerance, quality of life and activities of daily living. It has been shown to reduce healthcare utilisation and is very cost effective. Unfortunately, pulmonary rehabilitation has not been universally available in England, and the Strategy Consultation document ${ }^{9}$ encourages its wider availability. Publication of more detailed guidance regarding the specification of a high quality pulmonary rehabilitation service is being planned.

\section{Reducing psychological stress}

Many patients with COPD have depression and anxiety; 25\% are clinically depressed and the incidence of depression may be higher in patients with functional limitation. It is important to diagnose these patients.

The Strategy Consultation document ${ }^{9}$ and the NICE guidelines ${ }^{11}$ advise that patients should have access to a range of interventions including cognitive behavioural therapy and pharmacological treatments. It is recommended that a clinical psychologist be included in the multidisciplinary pulmonary rehabilitation team.

\section{Self-management and self-care Hilary Pinnock}

People with COPD live with their slowly deteriorating condition over many decades. Of necessity, they and their families develop self-care strategies to deal as best they can with the tobacco dependence, increasing disability, unpredictable exacerbations, complex medication regimes, co-morbidity and social isolation. The Consultation on a Strategy for Services for COPD in England emphasises the key role of all healthcare professionals in providing not only clinically focused self-management advice, but also holistic support to enable individual patients to self-care more effectively. ${ }^{9}$

\section{Information for self-care}

Recommendation 11: Good-quality information should be provided at diagnosis and delivered in a format that any person can understand.

Effective self-care is underpinned by accurate and accessible information, tailored to the individual's disability, relevant to their personal circumstances and sensitive to their preferences for knowledge and autonomy. Key topics identified by people with COPD and their carers include education about the disease, management of breathlessness, pharmacological treatments, management of exacerbations, psychological support, and guidance on welfare benefits. ${ }^{9}$ Education should start at the point of diagnosis and be extended appropriately as the disease evolves.

Useful sources of information include:

- the British Lung Foundation website (http://www.lunguk.org) includes written and video resources on COPD. ${ }^{45}$

- NHS Choices (http://www.nhs.uk), ${ }^{46}$ for information on healthy lifestyles, specific diseases and NHS services. An Information Prescription is an NHS initiative which aims to collate information specifically tailored to the individual patients' needs. Although intended to be compiled in discussion with a clinician, an online version enables a patient to choose the topics and services in which they are interested. ${ }^{47}$

\section{Managing their condition}

Recommendation 16: People with COPD should be encouraged to learn how to help manage their condition themselves..

\section{Lifestyle choices}

Smoking status should be checked at every COPD review, and brief advice given to those who continue to smoke. ${ }^{44}$ Useful guidance is available from http://www.theipcrg.org/smoking/ index.php.

Increasing breathlessness, reduced activity, and consequent deconditioning are not the only barriers to remaining active: practical solutions may be needed to overcome practical problems (e.g. top floor flats with no lifts). Patients should be encouraged to set their own goals as a target for improvement.

\section{Using medication}

Patients need information about their treatment, including how and when to take it, and discussion on any safety concerns. Reviewing inhaler technique annually is only helpful if action is taken to address problems - changing to an alternative device may be more effective than repeatedly correcting poor technique.

\section{Self-management of exacerbations}

Self-management education - including action plans about when and how to adjust and/or start medication in case of an exacerbation - reduces hospital admissions and significantly improves breathlessness and respiratory-related quality of life..$^{48}$

- Recognising deterioration: There are no physiological measures which predict exacerbations reliably, so patients are asked to monitor their symptoms (increased breathlessness, and increased quantity and purulence of sputum). Tools such as sputum colour charts may help patients differentiate exacerbations from 'bad days' with COPD.

- Taking action: Patients vary in the degree of autonomy that they wish to accept. Most will be happy to keep emergency supplies of steroids and antibiotics, though some will prefer to talk with a clinician before commencing treatment (see Figure 7). When to seek urgent advice is equally important.

Self-management plans should be reviewed regularly and revised as COPD progresses. Ongoing trials are testing whether tele-monitoring can reduce admissions by supporting selfmanagement. ${ }^{49} \mathrm{~A}$ Met Office initiative uses data about prevalent viruses combined with forecast cold weather to predict high risk of admissions so that patients can be prepared..$^{50}$ 
Figure 7. The Plymouth self-management plan (reproduced with the permission of Dr Rupert Jones).

\section{COPD Action Plan}

\begin{tabular}{|c|c|c|c|c|c|}
\hline \multirow{4}{*}{$\begin{array}{l}\text { WHAT ACTION TO TAKE IF YOUR } \\
\text { SYMPTOMS GET WORSE: } \\
\text { Step } 1 \\
\text { Check the colour of your sputum: } \\
\text { Cough sputum onto a white tissue. } \\
\text { If your sputum colour has changed from } \\
\text { clear or pale to a darker shade e.g. yellow } \\
\text { or green : start ANTIBIOTICS. }\end{array}$} & \multirow{2}{*}{$\begin{array}{l}\text { Step } 2 \\
\text { Symptoms }\end{array}$} & \multicolumn{3}{|c|}{ Look at table } & \multirow{3}{*}{$\begin{array}{l}\text { WARNING } \\
\text { At any time if you get } \\
\text { Severe symptoms: } \\
\text { If you have symptoms in the red ACTION } \\
\text { column, have tried medication and you are } \\
\text { not getting better, please contact your } \\
\text { doctor/nurse for an urgent appointment. }\end{array}$} \\
\hline & & OK & CAUTION & ACTION & \\
\hline & $\begin{array}{l}\text { Breathless- } \\
\text { ness }\end{array}$ & $\begin{array}{l}\text { Normal/ } \\
\text { Usual }\end{array}$ & $\begin{array}{l}\text { Worse } \\
\text { than } \\
\text { usual }\end{array}$ & $\begin{array}{l}\text { Much } \\
\text { worse } \\
\text { than } \\
\text { usual } \\
\end{array}$ & \\
\hline & Cough & \begin{tabular}{l|} 
Normall \\
Usual
\end{tabular} & $\begin{array}{l}\text { More } \\
\text { than } \\
\text { usual }\end{array}$ & $\begin{array}{l}\text { Much } \\
\text { more } \\
\text { than } \\
\text { usual } \\
\end{array}$ & $\begin{array}{l}\text { doctor/nurse for an urgent appointment. } \\
\text { EMERGENCY }\end{array}$ \\
\hline & \multirow{2}{*}{\multicolumn{4}{|c|}{$\begin{array}{l}\text { If all of your symptoms are in the green OK } \\
\text { column continue usual treatment. }\end{array}$}} & $\begin{array}{l}\text { If you have any of the following: } \\
\text { Very short of breath }\end{array}$ \\
\hline & & & & & $\begin{array}{l}\text { - Chest pains } \\
\text { - High fever }\end{array}$ \\
\hline & \multirow{3}{*}{\multicolumn{4}{|c|}{$\begin{array}{l}\text { If any of your symptoms are in the } \\
\text { orange CAUTION column: } \\
\text { Increase your RELIEVER TREATMENT, } \\
\text { take regular up to maximum dose. Keep a } \\
\text { close eye on your symptoms, if you improve } \\
\text { within } 2 \text { days resume usual treatment. }\end{array}$}} & $\begin{array}{l}\text { - Feeling of agitation, fear, } \\
\text { drowsiness or confusion }\end{array}$ \\
\hline $\begin{array}{l}\text { Maximum dose.................times per day } \\
\text { Maximum dose................ times per day }\end{array}$ & & & & & DIAL 999 AMBULANCE \\
\hline$\overline{\text { ANTIBIOTICS }}$ & & & & & - \\
\hline $\begin{array}{l}\text { Please take your home supply or obtain } \\
\text { a prescription without delay from the } \\
\text { surgery. }\end{array}$ & \multicolumn{4}{|c|}{$\begin{array}{l}\text { If NO improvement } \\
\text { start PREDNISOLONE. }\end{array}$} & 6000 \\
\hline $\begin{array}{l}\text { PREDNISOLONE } \\
\text { Take } 30 \mathrm{mg} \text { once daily }(6 \times 5 \mathrm{mg} \text { tablets) } \\
\text { For 5-10 days. }\end{array}$ & \multicolumn{4}{|c|}{$\begin{array}{l}\text { If any of your symptoms are in the } \\
\text { red ACTION column } \\
\text { Take maximum reliever treatment and } \\
\text { start PREDNISOLONE immediately. }\end{array}$} & $\begin{array}{l}\text { Oxygen } \\
\text { In an emergency please do not use high } \\
\text { flow oxygen. } \\
\text { Give sufficient oxygen to reach the } \\
\text { target saturation: ........... } \\
\text { (usual range } 88-92 \% \text { ) }\end{array}$ \\
\hline
\end{tabular}

\section{Support for self-care}

Recommendation 16 (cont): ....and how to have positive interactions with healthcare professionals and others about their condition.

People with respiratory long-term conditions value the support of a trusted clinician, ${ }^{51}$ and healthcare services need to ensure flexible access to professional advice. ${ }^{52}$ A face-to-face consultation may be required to deal with an exacerbation; on other occasions a brief telephone call or e-mail communication may suffice to answer a query. ${ }^{51} \mathrm{NHS}$ choices includes web-based resources to support self-care. ${ }^{53}$

Recommendation 16 (cont): They should also be encouraged to engage with others who have COPD in order to promote exchanges of information, support and advice.

Peer support is helpful, and many patients value the on-going support of their local BreatheEasy group. ${ }^{54}$ 'Expert patient' courses teach generic skills of relevance to people with COPD. ${ }^{55}$

Personalised care plans

It has been proposed that all people with long-term conditions, including COPD, should have a Personalised Care Plan (PCP). ${ }^{56}$ PCPs are owned by the patient, reflect their goals, and are tailored to individual circumstances. A clinical action plan advising on emergency management is likely to be a core component of a PCP, but in complex situations plans would also include details of care services, social needs and, if relevant, advanced care planning. Whether or not PCPs for COPD patients provide additional benefits over self-management or action plans is unknown.

\section{Management of acute exacerbations}

Kevin Gruffydd-Jones and Sarah-Jane Peffers

Definition

An acute exacerbation is defined by the Strategy Consultation document as a sustained worsening of an individual's symptoms from their usual stable state which is rapid in onset. ${ }^{9}$

COPD exacerbations are a burden on the individual patient and on health services throughout the world, and are associated with faster disease progression, worsening quality of life and increased mortality.

COPD was the second highest cause of hospital admissions in $2007 / 2008,{ }^{2}$ with $15 \%$ of patients dying within three months of admission..$^{57}$

The Consultation document makes several recommendations regarding the management of acute exacerbations of COPD, some of which are relevant to primary care: 
Recommendation 17: The quality of the identification and management of exacerbations should be improved and all people with COPD who have an exacerbation should be reviewed afterwards to ensure that their treatment remains optimal and relapses are reduced to a minimum

Recommendations 18: All people with COPD in respiratory failure should be issued with oxygen alert cards, and ambulance staff should be able to recognise and respond appropriately to respiratory failure in COPD.

Recommendation 19: People with COPD should receive a specialist respiratory review when acute episodes have required referral to hospital. They should be assessed for management by early discharge schemes, or by a structured hospital admission, to ensure that length of stay and subsequent readmission are minimised.

Recommendation 20: All people with acute respiratory failure should be identified and investigated promptly and offered treatment with non-invasive ventilation (NIV) with access to mechanical ventilation, if required.

\section{The need for early recognition of exacerbations}

Whilst most COPD exacerbations are treated in the community, about $50 \%$ of patients with an acute COPD exacerbation do not present to a healthcare professional. ${ }^{58}$ Detailed guidance for treatment is provided in the NICE guidelines, ${ }^{11}$ and the earlier treatment is started the less chance there is of hospital admission. ${ }^{59}$ Provision of individualised self-management strategies including action plans which help the patient to identify and treat early signs of an exacerbation can reduce hospital admissions ${ }^{60}$ (see above).

\section{Assessment}

Assessment should include:

- Level of consciousness

- Assessment of degree of breathlessness, (respiratory rate, use of accessory muscles)

- Degree of hypoxaemia (presence of cyanosis, oxygen saturation below 92\%)

- History and examination to exclude alternative diagnoses (e.g. pneumonia, pulmonary embolus) and to assess co-morbidities.

- Ability to cope at home during the course of an exacerbation (including degree of carer support available)

\section{Treatment}

\section{Patient self-management}

Many patients will have started management themselves by use of stand-by antibiotics for cough with purulent sputum, increased use of short-acting bronchodilator, and/or use of standby oral steroids and breathing exercises. The Strategy recommends that patients inform their usual healthcare professional within two days of starting their exacerbation therapy (see below).

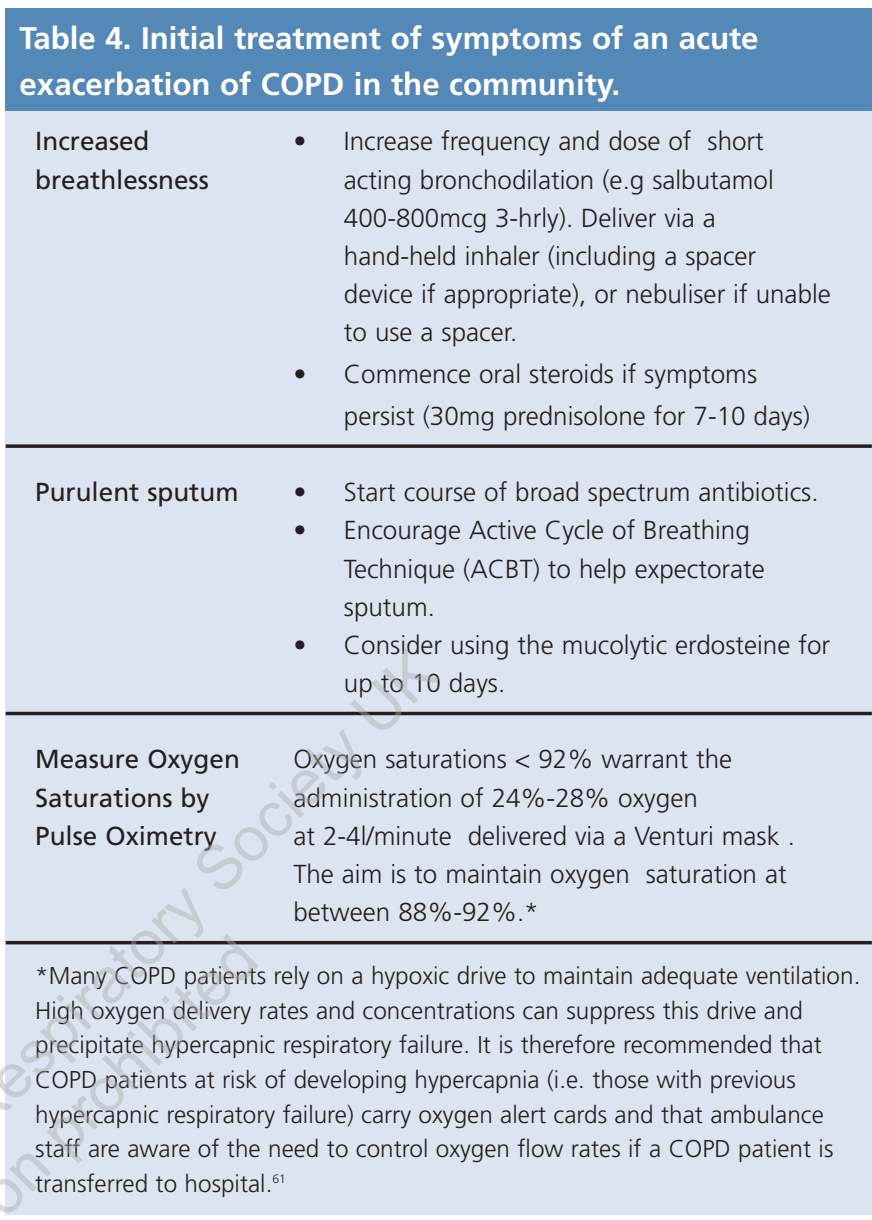

\section{Management in primary care}

After initial assessment, treatment should be initiated in line with national and local guidance (see Table 4).

Various factors are considered when deciding whether to treat the patient at home or in hospital (see Table 5). This may vary according to available home care support (e.g. "hospital at home" services).

\section{Review}

Where patients have been treated for an exacerbation in the community, the patient should be reviewed at least at the end of the initial treatment period (e.g. after one week of oral antibiotics and/or oral steroids) or sooner if the clinical condition warrants this. Further review at six weeks should include optimisation of pharmacological and non-pharmacological therapy and reinforcement of self-management education (see Figure 8).

\section{Hospital admission}

The detailed recommendations regarding in-patient management are beyond the scope of this primary care-focussed supplement, but they include:

- Prompt access to non-invasive ventilation (NIV) and/or mechanical ventilation for patients in acute respiratory failure.

- Review during admission by a member of the specialist respiratory team.

- Review of management of the acute condition and of comorbid conditions 


\begin{tabular}{|c|c|c|}
\hline Factor & Treat at home & Treat in hospital \\
\hline Able to cope at home & Yes & No \\
\hline Breathlessness & Mild & Severe \\
\hline General condition & Good & Poor/deteriorating \\
\hline Level of activity & Good & Poor/confined to bed \\
\hline Cyanosis & No & Yes \\
\hline Worsening peripheral oedema & No & Yes \\
\hline Level of consciousness & Normal & Impaired \\
\hline Already receiving LTOT* & No & Yes \\
\hline Social circumstances & Good & Living alone/not coping \\
\hline Acute confusion & No & Yes \\
\hline Rapid rate of onset & No & Yes \\
\hline $\begin{array}{l}\text { Significant co-morbidity } \\
\text { (particularly cardiac disease } \\
\text { and insulin-dependent diabetes) }\end{array}$ & No & Yes \\
\hline $\mathrm{SaO}_{2}<90 \%$ & No & Yes \\
\hline Changes on chest radiograph & No & Present \\
\hline Arterial pH level & $\geq 7.35$ & $<7.35$ \\
\hline Arterial $\mathrm{PaO}_{2}$ & $\geq 7 \mathrm{kPa}$ & $<7 \mathrm{kPa}$ \\
\hline
\end{tabular}

- Review of discharge arrangements including the requirement for continuing care in the community (including the provision of oxygen post admission, rehabilitation programmes, and psychosocial support).

- Review of chronic management including self-management advice.

\section{Review post-discharge}

Thirty-three percent of patients are readmitted to hospital within three months of an acute exacerbation of COPD. ${ }^{57}$ There is evidence that discharge procedures are inadequate and that some patients are left socially isolated and depressed. ${ }^{62}$ The UK National COPD Audit of $2008^{57}$ showed a median time to readmission of 38 days, with $25 \%$ of patients being readmitted within 20 days, thus suggesting that review should be carried out within three weeks of hospital discharge (see Figure 8). The Consultation document's recommendation of post-discharge review within six weeks $s^{9}$ may therefore be too lenient, and this may need to be reviewed before publication of the final Strategy document.

\section{Admission avoidance and early discharge schemes}

There are a variety of models of care available to minimise the impact of acute exacerbations of COPD. ${ }^{63}$ These include validated early assisted discharge schemes from hospital, and "hospital at home" admission avoidance schemes provided by specialist community teams or hospital outreach teams. These have the potential to reduce hospital admission rates and inpatient stays.
Figure 8. Features of a post-exacerbation review (adapted from the GOLD report ${ }^{31}$ by Dr Gruffydd-Jones).

- Optimise acute treatment including pharmacotherapy, provision of oxygen and pulmonary rehabilitation where appropriate.

- Optimise psychosocial support.

- Discuss/reinforce self-management education including the use of self-management plans.

- Consider discussion of possible palliative care (including end-of life issues if appropriate) including action to be taken if further exacerbations.

- Optimise chronic care to prevent exacerbations.

Such schemes are preferred by people with COPD and have proved to be a cheaper option than usual care. Other novel methods of care, such as telemedicine, could have the potential to identify exacerbations at an early stage, trigger early interventions and reduce the risk of hospital admission. ${ }^{49}$

\section{End-of-life care Patrick White and Jane Scullion}

Recommendation 21: There should be improved access to high-quality end-of-life care services that ensure equity in care provision for people with severe COPD, regardless of setting.

Recommendation 22: Access to information and appropriate support should be available to carers and those who are bereaved.

For people diagnosed with COPD it is inevitable that whilst they may or may not die from their condition they will certainly die with it. COPD is a chronic and progressive disease in which treatments are aimed mainly at improving symptoms but have little impact on disease progression. The treatment of advanced COPD is therefore essentially palliative. It can be seen to fit the basic tenets of palliative care although there are also specific end-of-life issues. Recommendations 21 and 22 link well with guidelines for end-oflife-care of people with non-malignant diseases. ${ }^{9,64}$ They emphasise the importance of access both to high quality end-of-life-care and to appropriate information and support for carers. The recommendations come with three associated action points (Actions 30-32) which propose piloting markers of a prognostic indicator, publishing core workforce skill requirements, and piloting and evaluating an end-of-life care pathway.

The recommendations and the actions highlight the challenge facing clinicians working with patients with advanced 
Table 6. Symptoms often experienced by patients with advanced COPD (Reproduced with permission from the Department of Health ${ }^{64}$.
- Breathlessness

- Fatigue

- Pain

- Insomnia
- Cough

- Anxiety and depression

- Fear and panic

- Weight loss / Cachexia
COPD. It is difficult to identify patients who are dying from COPD. For those who are identified, there is no recognised pathway of care, although the document ${ }^{9}$ includes the end-oflife care pathway of the Department of Health End of Life Care Strategy. ${ }^{64}$ An additional challenge concerns the palliation of symptoms, predominantly breathlessness (see Table 6). ${ }^{65}$ Breathlessness is the most important problem to people with advanced COPD and in many patients palliation of breathlessness should be addressed even before they can be defined as having reached the terminal phase of the disease. ${ }^{66}$ Whether palliation of breathlessness should be considered alongside end-of-life-care of COPD or should be considered in the mainstream management of the disease is an issue for further discussion. Palliation of breathlessness in advanced COPD will likely be confused with end-of-life-care, and it will not be easy for clinicians to consider it until they have started to think in terms of end-of-life-care. ${ }^{67} \mathrm{As}$ the palliation of breathlessness becomes more widely understood in COPD it is likely to be seen and treated separately.

Symptom control in advanced COPD requires an expertise which is often lacking in traditional care of the disease. ${ }^{68}$ COPD management is usually reactive and aimed at crisis intervention, whereas a palliative care approach should be more proactive. In order to manage symptoms, it is first necessary to look at patients' understanding of their disease, what they believe caused it and what they anticipate can be done about it. If we manage to address patients' perceptions of their condition we can more adequately assess general well-being and the likely effectiveness of treatments. It may be necessary to explore beyond the impact of dyspnoea and declining lung function. The role of social and emotional issues, the experience of panic attacks, and the fear of dying may be critical to wellbeing in advanced COPD. In this respect it is good to see the needs of carers addressed in the Strategy Consultation document. ${ }^{9}$ COPD is a disease with social ramifications beyond the individual affected especially in its advanced stages.

The Consultation document acknowledges the difficulty clinicians face in defining prognosis in advanced COPD and the impact that this is likely to have in determining when patients have reached the end stage of the disease. ${ }^{9}$ The document is positive about prognosis in referring to the BODE index ${ }^{33}$ as a tool for predicting mortality - though this is poorly supported by the Gold Standards Framework ${ }^{69}$ and by evidence provided by systematic reviews of end-of-life-care of COPD. ${ }^{70-72}$ BODE is not definitive in predicting mortality in the context of end-of-life care.
Even using the most severe category of the BODE index, $70 \%$ of subjects will still be alive at two years so it does not enable us to predict when patients will die.

The best indices of survival in advanced disease based on current evidence are more likely to be the generic characteristics of proximity of death - such as progressive loss of function and weight, and progressive symptoms. For a person with COPD we would therefore expect a poor prognosis in someone with severe airflow obstruction (MRC Dyspnoea score of 5) on long-term oxygen therapy (LTOT), with weight loss and increasing hospitalisations. These practical markers may incline us to initiate the discussion about end-of-life with the patient and their carers.

The End-of-Life Care chapter of the COPD Strategy Consultation document is welcome, because it highlights a problematic area of COPD care for clinicians, addressing many as yet unanswered questions, and it indicates the need for further key research in this important but largely uncharted area.

\section{Implementing the Strategy for COPD Services in England, measuring outcomes, and commissioning care}

\section{Rupert Jones}

\section{COPD Strategy objectives}

The key objectives of the Strategy are:

- Prevention and early identification

- Good quality early diagnosis

- High quality care and support following diagnosis

- Improving access to end-of-life services

The role of the Strategy is to ensure that organisations which provide respiratory services have a framework which defines the standards for those services. The Consultation on the Strategy for Services for COPD in England ${ }^{9}$ sets out standards for services, including clinical standards set by NICE, ${ }^{11}$ and how these standards are to be implemented.

\section{The background to implementation}

The Strategy Consultation document was published as a draft version in February 2010,9 but the actual Strategy and its implementation plan has yet to be finalised and launched.

The White paper 'Equity and excellence: Liberating the NHS'10 proposes far-reaching changes to the UK NHS including commissioning by GPs and phasing out of Strategic Health Authorities (SHAs) and Primary Care Trusts (PCTs). Ensuring quality of services remains an important element of government policy, but with new emphasis on measuring outcomes, rather than process, especially Patient-Reported Outcome Measures (PROMS) and patient experience. There will be an increased role for patients in designing, delivering and monitoring the service as well as strengthening patient choice. Proposals are made to reform long-term prevention strategies in partnership with other fields such as social care and public health, all to be delivered with reduced management costs.

The NHS will have to save $f 20$ billion over the next three 
years (a saving of approximately $£ 1,000$ for every person in England every year). Implementing all of the recommendations in the Strategy Consultation document ${ }^{9}$ may increase healthcare costs in the short term but reduce them in the long term. Direct savings can be made by reducing inappropriate drug and oxygen therapy while savings are anticipated through strategies to reduce exacerbations, admissions and disease progression such as smoking cessation, rehabilitation and drug treatments. The impact assessment published in February 2010 has predicted that over 10 years the net benefit of implementing the Strategy to the NHS will be $f 1,075 m$ (range $£ 235-3,407 m$ ). ${ }^{73}$

\section{Implementation Mechanisms}

The implementation of the strategy will occur at different levels.

\section{Clinical networks}

Regional SHA respiratory clinical leads have been appointed to establish a network of managers and clinicians to oversee the service development. How each region operates will vary in practice, but they will seek to bring together services in primary, secondary and intermediate care as well as private providers. Independent third sector providers are expected to increase in number and will need to be assessed in conjunction with existing NHS services. As PCTs are phased out, the services they currently provide will need to be realigned either to be under the aegis of a GP consortium, hospital trust or becoming an independent social enterprise company.

Particular attention will be paid to the key priorities for implementation from the NICE COPD guideline ${ }^{11}$ :

- Diagnose COPD and confirm airflow obstruction by postbronchodilator spirometry

- Stop smoking

- Promote effective inhaled therapy

- Provide pulmonary rehabilitation for all who need it, including those who have had a recent hospitalisation for an acute exacerbation

- Use non-invasive ventilation (NIV) for persistent hypercapnic ventilatory failure during exacerbations not responding to medical therapy

- Manage exacerbations

- Ensure multi-disciplinary working

The clinical leads will assess services in terms of process and outcomes;

Process:

What services are currently in place?

What are the gaps in provision including accessibility for services such as spirometry, structured care, pulmonary rehabilitation and NIV?

Outcomes:

The quality of services will be measured using common assessment methods (see Metrics section below). Services which provide an efficient and effective service to improve patientcentred outcomes, reduce costs and disease progression, will be identified and emulated. Standards are being set for the quality of the service to guide commissioners and those assessing the service; many standards are defined in the Strategy Consultation document, ${ }^{9}$ and others - such as the programme for Physiological Measurement standards - are ongoing.

\section{Metrics}

There is an ongoing stream of work to define best outcome measures in a range of areas including the following:

(i) Quality of diagnostic services:

Assess diagnostic standard spirometry provision as defined by the Consultation document ${ }^{9}$ and subsequent guidance. Clinical leads will assess the quality of services irrespective of where they are delivered.

(ii) Data recording:

Data recording in primary care and in hospital services will be checked, including NICE-approved items such as the MRC dyspnoea scale and exacerbation frequency. NICE is now revising the Quality Outcomes Framework (QOF) markers for COPD.

(iii) Structured care:

The recording of patient reviews at recommended intervals depending on disease severity, and items such as offering smoking cessation to current smokers and pulmonary rehabilitation for those with MRC dyspnoea score of 3 or above will be required. Another marker is the documented provision of care plans including self-management advice and reviews postexacerbation/admission.

(iv) In-patient care:

The metrics in secondary care may well follow those used in the RCP audits $^{74,75}$ including admission rates and duration, the proportion of in-patients managed by a chest specialist, readmission rates within three months, and mortality (both inpatient and within three months post-admission). The 24 hour availability and patient experience of NIV is a likely marker.

(v) Accessible, high quality local services:

Availability of services such as pulmonary rehabilitation and oxygen assessment services will be important. Suitable metrics may include the number of patients prescribed oxygen, the proportion who had a formal assessment, and the proportion on short burst oxygen.

\section{Commissioners}

Commissioning of services will be overseen by a new national independent board. Regional respiratory clinical leads will have a role in monitoring services and establishing clinical networks to promote better service integration and delivery of respiratory services. The $\mathrm{DOH}$ will be issuing clear guidance to commissioners in a document anticipated at the end of 2010.

GP consortia will have responsibility for commissioning services for people with COPD. GP consortia will have a nationally-set budget and there will be a personal health budget for people with long-term conditions to ensure that those providing for these patients have the appropriate resources.

\section{Summary}

The UK NHS can no longer afford to ignore COPD. Implementing the recommendations in the Consultation on a Strategy for Services for COPD in England should reduce the inordinate and growing costs of 
COPD, both human and financial. New systems of commissioning, provision and monitoring of services in a rapidly changing NHS are outlined. A new unified approach to provision of high quality and uniform COPD services is being developed. To deliver better services, primary care will have to work more closely with other GPs in consortia and with clinical networks. It is hoped that incentives such as QOF payments and GP commissioning will be used to drive increased quality of care. There will be a new emphasis on 'outcomes' rather than 'process', particularly patient-related outcomes and patient experience.

\section{Conflict of Interest declarations}

RJ has been paid to take part in educational activities related to COPD for Altana, Astra Zeneca (AZ), Boehringer Ingelheim (BI), GlaxoSmithKline (GSK), Novartis, Nutricia, Pfizer, TEVA, Tejin and Chiesi in the last three years. RJ is a consultant to the global emPOWER educational programme supported by Pfizer and Bl.

KG-J is a member of the NICE COPD Guidelines Committee, and the Medicines Management Group for the COPD Clinical Strategy. He has spoken and acted as consultant for GSK, Merck Sharpe \& Dohme (MSD), BI, AZ, Chiesi, Pfizer and Novartis. $\mathrm{HP}$ has received fees for lecturing or attending advisory groups from GSK, $\mathrm{AZ}, \mathrm{BI}$, and has been sponsored to attend conferences by AZ, BI/Pfizer and GSK.

SJP has received speaker honoraria and travel support to conferences from BI, Cheisi, GSK, Pfizer and AZ.

JL has received speaker honoraria from AZ, GSK, and BI. She has also co-authored educational resources funded by the Primary Care Respiratory Society UK

JS has received honorarium and travel grants from AZ, GSK, Pfizer, BI, Novartis, Quintiles, and Teva.

PW has received speaker honoraria and support for travel to scientific conferences from AZ, BI UK, GSK, and Pfizer UK.

SH has received funding as a speaker, advisor, as well as receiving travel bursaries from Altana, AZ, BI, GSK, MSD, Novartis, Pfizer and Chiesi in the last three years. He has also indirectly received Department of Health funding for work within the IMPRESS collaborative.

\section{Acknowledgement}

The authors would like to acknowledge the support - including information provided, encouragement and sponsorship - of the Department of Health, London, England. They also wish to acknowledge Anne Smith, Bronwen Thompson and Laraine Holdsworth from the PCRS-UK for their advice and encouragement.

\section{Funding}

This supplement has been supported by the UK Department of Health in England

\section{References}

1. British Thoracic Society. Burden of Lung Disease 2006

2. Health Care Commission. Clearing the air: A national study of chronic obstructive pulmonary disease. 2006.

3. British Lung Foundation. Invisible Lives. London: British Lung Foundation 2007.

4. Sullivan SD, Ramsey SD, Lee TA. The economic burden of COPD. Chest 2000;117(2 Suppl):5S-9S. http://dx.doi.org/10.1378/chest.117.2_suppl.5S

5. Price LC, Lowe D, Hosker HSR et al. UK National COPD Audit Impact of hospital resources and organisation of care on patient outcome following admission for acute COPD exacerbation. Thorax 2003;61:837-42.

6. International Monetary Fund. World Economic Outlook: Crisis and Recovery: International Monetary Fund Report, April 2009.

7. Department of Health. Annual Report of the Chief Medical Officer 2004 on the state of public health. 2005

8. Gruffydd-Jones K. A national strategy for the management of chronic obstructive pulmonary disease (COPD) in England: aiming to improve the quality of care for patients. Prim Care Resp J 2008;17(Suppl 1):S1-S8. http://dx.doi.org/ 10.3132/pcrj.2008.00071
9. Department of Health / Respiratory Team. Consultation on a Strategy for Services for Chronic Obstructive Pulmonary Disease (COPD) in England. London, Department of Health, Crown Copyright, 2010. 296481

10. Department of Health. Equity and excellence: Liberating the NHS. ISBN 9780101788120. 12-7-2010. London, Crown Copyright.

11. National Clinical Guideline Centre. (2010) Chronic obstructive pulmonary disease: management of chronic obstructive pulmonary disease in adults in primary and secondary care London: National Clinical Guideline Centre. www.ncgc.ac.uk/Guidelines/Published/20

12. West $R$, McNeill $A$, Raw M. Smoking cessation guidelines for health professionals: an update. Thorax 2000;55(12):987-99. http://dx.doi.org/10.1136/thorax.55.12.987

13. Prochaska JO. Stages and processes of self-change of smoking: toward an integrative model of change. J Consult Clin Psychol 1983;51(3):390-5. http://dx.doi.org/10.1037/0022-006X.51.3.390

14. Glynn TJ. How to help your patients stop smoking. A National Cancer Institute manual for physicians. US Department of Health and Human Services. Washington, DC, 1989.

15. Enright P. The use and abuse of office spirometry. Prim Care Resp J 2008;17(4):23842. http://dx.doi.org/10.3132/pcrj.2008.00065

16. Enright P. Check the FEV1 for all adult smokers, even patients without respiratory symptoms. Prim Care Resp J 2010;19(2):91-2. http://dx.doi.org/ 10.4104/pcrj.2010.00037

17. Levy ML, Quanjer PH, Booker R, Cooper BG, Holmes S, Small I. Diagnostic Spirometry in Primary Care: Proposed standards for general practice compliant with American Thoracic Society and European Respiratory Society recommendations. Prim Care Resp J 2009;18(3):130-47. http://dx.doi.org/10.4104/pcrj.2009.00054

18. Price $D$, Crockett $A$, Arne $M$, et al. Spirometry in primary care case-identification, diagnosis and management of COPD. Prim Care Resp J 2009;18(3):216-23. http://dx.doi.org/10.4104/pcrj.2009.00055

19. Jenkins CR. Spirometry performance in primary care: the problem, and possible solutions. Prim Care Resp J 2009;18(3):128-9. http://dx.doi.org/10.4104/ pcrj.2009.00057

20. Jordan RE, Lam K-bH, Cheng KK, et al. Case finding for chronic obstructive pulmonary disease: a model for optimising a targeted approach. Thorax 2010;65(6):492-8. http://dx.doi.org/10.1136/thx.2009.129395

21. Royal College of Physicians of London, BTS and BLF. The National Chronic Obstructive Pulmonary Disease Audit 2008: survey of COPD care within UK General Practices 2008.

22. Pinnock H. PCRS-UK National Strategy Quick Reference Guide. PCRS-UK. 2010. http://www.pcrs-uk.org/copd_qrg/index.php (accessed 4th October 2010)

23. National Statistics (2006) Death registrations in England and Wales: 2005, causes; taken from Health Statistics Quarterly 30 http://www.statistics.gov.uk/downloads/ theme_health/HSQ30.pdf (accessed October 2010)

24. Anthonisen NR, Connett JE, Enright PL, Manfreda J. Hospitalizations and mortality in the Lung Health Study. Am J Respir Crit Care Med 2002;166(3):333-9. http://dx.doi.org/10.1164/rccm.2110093

25. Svanes $C$, Sunyer J, Plana $E$, et al. Early life origins of chronic obstructive pulmonary disease. Thorax 2010;65(1):14-20. http://dx.doi.org/10.1136/thx.2008.112136

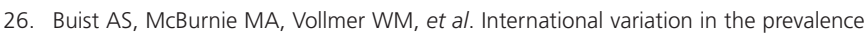
of COPD (the BOLD Study): a population-based prevalence study. Lancet 2007; 370(9589):741-50. http://dx.doi.org/10.1016/S0140-6736(07)61377-4

27. Hyland ME, Jones RCM, Hanney KE. The Lung Information Needs Questionnaire: Development, preliminary validation and findings. Respir Med 2006;100(10):180716. http://dx.doi.org/10.1016/j.rmed.2006.01.018

28. Tashkin D, Rennard S, Hays JT, Ma W, Lee TC. Efficacy and safety of varenicline for smoking cessation in patients with mild to moderate COPD. Chest 2009; 136(4):151S-151b.

29. Martinez FJ, Raczek AE, Seifer FD, et al. Development and initial validation of a selfscored COPD Population Screener Questionnaire (COPD-PS). COPD 2008;5(2):85-95.

30. Price DB, Tinkelman DG, Halbert RJ, et al. Symptom-based questionnaire for identifying COPD in smokers. Respiration 2006;73(3):285-95 http://dx.doi.org/10.1159/000090142

31. Global initiative for chronic Obstructive Lung Disease. Global strategy for the diagnosis, management and prevention of COPD. 2009. www.goldcopd.com

32. Jones RC, Dickson-Spillmann M, Mather MJ, Marks D, Shackell BS. Accuracy of diagnostic registers and management of chronic obstructive pulmonary disease: the 
Devon primary care audit. Respir Res 2008;9:62. http://dx.doi.org/10.1186/14659921-9-62

33. Celli BR, Cote CG, Marin JM, et al. The body-mass index, airflow obstruction, dyspnea, and exercise capacity index in chronic obstructive pulmonary disease. New Engl J Med 2004;350:1005-12. http://dx.doi.org/10.1056/NEJMoa021322

34. Jones RC, Donaldson GC, Chavannes NH, et al. Derivation and Validation of a Composite Index of Severity in Chronic Obstructive Pulmonary Disease The DOSE Index. Am J Respir Crit Care Med 2009;180:1189-95. http://dx.doi.org/10.1164/rccm.200902-02710C

35. Puhan MA, Garcia-Aymerich J, Frey M, et al. Expansion of the prognostic assessment of patients with chronic obstructive pulmonary disease: the updated BODE index and the ADO index. Lancet 2009;374(9691):704-11. http://dx.doi.org/10.1016/S01406736(09)61301-5

36. Pearson M. Chronic obstructive Pulmonary Disease. National clinical guideline on management of chronic obstructive pulmonary disease in adults in primary and secondary care. Thorax 2004;59(Suppl1):1-232.

37. Celli BR, MacNee W, Agusti A et al. Standards for the diagnosis and treatment of patients with COPD: a summary of the ATS/ERS position paper. Eur Respir J 2004;23:932-46. http://dx.doi.org/10.1183/09031936.04.00014304

38. Bridevaux PO, Gerbase MW, Probst $\mathrm{HN}$, et al. Long term decline in lung function, utilisation of care and quality of life in modified GOLD stage 1 COPD. Thorax 2008;63(9):768-74.http://dx.doi.org/10.1136/thx.2007.093724

39. British Thoracic Society, Scottish Intercollegiate Guidelines Network. British Guideline on the Management of Asthma. Thorax 2008;63(Suppl4):iv1-121. http://dx.doi.org/ 10.1136/thx.2008.097741

40 GINA. The global Strategy for Asthma Management and Prevention, Global Initiative for Asthma (GINA). See http://www. ginasthma.org

41. Jones $P$, Harding G, Wiklund I, Berry P, Leidy N. Improving the process and outcome of care in COPD: development of a standardised assessment tool. Prim Care Resp J 2009;18(3):208-15. http://dx.doi.org/10.4104/pcrj.2009.00053

42. Wagner $\mathrm{EH}$. Chronic disease management: What will it take to improve care for chronic illness? Effective Clinical Practice 1998;1(1):2-4.

43. Diagnosis and Management of chronic obstructive pulmonary disease in primary care. Primary Care Respiratory Society UK 2010. www.pcrs-uk.org.

44. Pinnock $H$ (editor), van Schayck O (Chairman) for the IPCRG Smoking Cessation Guidance group. Tackling the Smoking Epidemic. Aberdeen; IPCRG, 2007. Available from http://www.theipcrg.org/smoking/index.php (accessed February 2010)

45. British Lung Foundation. Living with chronic obstructive pulmonary disease. Available from http://www.lunguk.org/you-and-your-lungs/conditions-and-diseases

46. National Health Service. NHS Choices: Chronic obstructive pulmonary disease. Available from http://www.nhs.uk/conditions/Chronic-obstructive-pulmonarydisease/Pages/Introduction.aspx (Accessed March 2010)

47. National Health Service. NHS Choices: Create an information prescription for chronic obstructive pulmonary disease. Available from http://www.nhs.uk/ Pathways/copd/Pages/InfoScriptCreate.aspx. (Accessed March 2010)

48. Effing T, Monninkhof EEM, van der Valk PP, et al. Self-management education for patients with chronic obstructive pulmonary disease. Cochrane Database of Systematic Reviews 2007, Issue 4. Art. No.: CD002990. http://dx.doi.org/ 10.1002/14651858.CD002990.pub2

49. Pinnock H, Hanley J, Lewis S, et al. The impact of a telemetric chronic obstructive pulmonary disease monitoring service: randomised controlled trial with economic evaluation and nested qualitative study. Prim Care Resp J 2009;18:233-5. http://dx.doi.org/10.4104/pcrj.2009.00040

50. The Met Office. Healthy Outlook COPD Forecast Alert Service. Available from http://www.metoffice.gov.uk/health/copd_forecasting.html (Accessed March 2010)

51. Kielmann T, Huby G, Powell A, et al. From support to boundary: a qualitative study of the border between self care and professional care. Pat Ed Counse/ 2010;79:5561. http://dx.doi.org/10.1016/j.pec.2009.07.015

52. Kennedy A, Rogers A, Bower P. Support for self care for patients with chronic disease. BMJ 2007;337:968-70.

53. National Health Service. Your Health, Your Way: Your NHS guide to long-term conditions and self care. NHS Choices. http://www.nhs.uk/Planners/Yourhealth/ Pages/Yourhealth.aspx (accessed March 2010)

54. British Lung Foundation. Breathe Easy. Available from http://www.lunguk.org/ supporting-you/breathe-easy (Accessed March 2010)

55. Department of Health. The expert patient: A new approach to chronic disease management for the 21st century. London: $\mathrm{DoH}, 2001$

56. Department of Health. Supporting people with long term conditions: commissioning personalised care planning - a guide for commissioners. DOH 2009. Available from http://www.dh.gov.uk (accessed March 2010)

57. Royal College of Physicians Clinical Effectiveness Unit National COPD Audit 2008. Royal College of Physicians.

58. Seemungal TAR, Donaldson GC, Bhowmik A, Jeffries DJ, Wedzicha JA. Time course and recovery of exacerbations in patients with chronic obstructive pulmonary disease. Am J Respir Crit Care Med 2000;161:1608-13

59. Wilkinson TM, Donaldson GC, Hurst JR, Seemungal TA, Wedzicha JA. Early therapy improves outcomes of exacerbations of chronic obstructive pulmonary disease. Am $J$ Respir Crit Care Med 2004;169(12):1298-303. http://dx.doi.org/10.1164/ rccm.200310-14430C

60. Gadoury MA, Schwartzman K, Rouleau M, et al. Self-management reduces both short- and long-term hospitalisation in COPD. Chronic Obstructive Pulmonary Disease axis of the Respiratory Health Network, Fonds de la recherche en santé du Québec (FRSQ). Eur Respir J 2005; 26(5):853-7. http://dx.doi.org/10.1183/ 09031936.05.00093204

61. O'Driscoll, BR, Howard, LS, Davison AG. BTS guideline for emergency oxygen use in adult patients. Thorax 2008;63(suppl6):vi1-vi68. http://dx.doi.org/10.1136/thx.2008.102947

62. Gruffydd-Jones K, Langley-Johnson C, Dyer C, Badlan K, Ward S. What are the needs of patients following discharge from hospital after an acute exacerbation of chronic obstructive pulmonary disease (COPD)? Prim Care Resp J 2007;16(6):363-9. http://dx.doi.org/10.3132/pcrj.2007.00075

63. British Thoracic Society Guideline Development Group. Intermediate Care - Hospitalat-Home in chronic obstructive pulmonary disease. British Thoracic Society Guidleline. Thorax 2007;62:200-10. http://dx.doi.org/10.1136/thx.2006.064931

64. Department of Health. End of life care strategy - promoting high quality care for all adults at the end of life. 2008 Department of Health, London.

65. Elkington $\mathrm{H}$, White $\mathrm{P}$, Addington-Hall J, Higgs R, Edmonds P. The healthcare needs of chronic obstructive pulmonary disease patients in the last year of life. Pall Med 2005; 19:485-91. http://dx.doi.org/10.1191/0269216305pm1056oa

66. White $P$, White $S$, Edmonds $P$, et al. Palliative care or end of life care in advanced COPD? A prospective community survey. Br J Gen Pract 2010. (In press)

67. Booth S, Moosavi SH, Higginson IJ. The etiology and management of intractable breathlessness in patients with advanced cancer: a systematic review of pharmacological therapy. Nat Clin Pract Oncol 2008;5(2):90-100. http://dx.doi.org/10.1038/ncponc1034

68. Dean MM. End-of-life care for COPD patients. Prim Care Resp J 2008;17(1):46-50 http://dx.doi.org/10.3132/pcrj.2008.00007

69. Gold Standards Framework and Royal College of General Practitioners. Prognostic Indicator Guidance Paper, version 5. National Gold Standards Framework Centre. 2008, England. http://www.goldstandardsframework.nhs.uk/Resources/ Gold\%20Standards\%20Framework/PrognosticIndicatorGuidancePaper.pdf (Accessed 22 October 2010).

70. Rocker GM, Sinuff T, Horton R, Hernandez P. Advanced chronic obstructive pulmonary disease: innovative approaches to palliation. I Palliat Med 2007;10(3):783-97. http://dx.doi.org/10.1089/jpm.2007.9951

71. Seamark DA, Seamark CJ, Halpin DM. Palliative care in chronic obstructive pulmonary disease: a review for clinicians. $J \quad R$ Soc Med 2007;100(5):225-33. http://dx.doi.org/10.1258/jrsm.100.5.225

72. Curtis JR. Palliative and end-of-life care for patients with severe COPD. Eur Respir J 2008;32(3):796-803. http://dx.doi.org/10.1183/09031936.00126107

73. Department of Health / Respiratory Team. Consultation on a Strategy for services for Chronic Obstructive Pulmonary Disease (COPD) in England-Consultation Impact Assessment. Gateway 11943. 10-2-2010. London, Department of Health.

74. Royal College of Physicians and British Thoracic Society. Report of the 2003 National COPD Audit. 2003. London, The Clinical Effectiveness and Evaluation Unit, Royal College of Physicians.

75. Royal College of Physicians. Report of The National Chronic Obstructive Pulmonary Disease Audit 2008: Resources and Organisation of care in Acute NHS units across the UK. 2008. London, Royal College of Physicians.

\section{Available online at http://www.thepcrj.org}

